OPEN ACCESS

Edited by:

Hongbiao Cui

Anhui University of Science and

Technology, China

Reviewed by:

Changfeng Ding,

Institute of Soil Science (CAS), China

Xuebo Zheng,

Tobacco Research Institute

(CAAS), China

*Correspondence:

DaJuan Wan

dajuanwan@163.com

Specialty section:

This article was submitted to

Soil Processes,

a section of the journa

Frontiers in Environmental Science

Received: 01 February 2021 Accepted: 17 March 2021

Published: 20 April 2021

Citation:

Wang C, Wan D, Cao X, Wang H,

Chen J, Ouyang N, Zhang $Y$ and

Tan C (2021) Spatial Distribution

Characteristic of Antimony in Typical

Paddy Soil of Eastern Hunan Province,

China. Front. Environ. Sci. 9:661148.

doi: $10.3389 /$ fenvs. 2021.661148

\section{Spatial Distribution Characteristic of Antimony in Typical Paddy Soil of Eastern Hunan Province, China}

\author{
ChenRan Wang ${ }^{1}$, DaJuan Wan ${ }^{1 *}$, XueYing Cao ${ }^{2}$, Huan Wang ${ }^{1}$, JiaQi Chen ${ }^{1}$, \\ NingXiang Ouyang ${ }^{3}$, YangZhu Zhang ${ }^{3}$ and ChangYin Tan ${ }^{1}$ \\ ${ }^{1}$ College of Geographic Science, Hunan Normal University, Changsha, China, ${ }^{2}$ Rural Vitalization Research Institute, \\ Changsha University, Changsha, China, ${ }^{3}$ College of Resources \& Environment, Hunan Agricultural University, Changsha, \\ China
}

Considering the eastern part of Hunan Province as the research area, 34 sampling sites were set up, 198 samples were collected from representative paddy soil, the distribution characteristics of antimony (Sb) were studied. The results showed that: (1) The content of $\mathrm{Sb}$ on the surface of paddy soil ranging from 0.07 to $11.00 \mathrm{mg} / \mathrm{kg}$ and the geometric mean was $1.56 \mathrm{mg} / \mathrm{kg}$. (2) The distribution of contents of Sb in paddy soil in different areas was shown as Yueyang $>$ Changsha $>$ Zhuzhou $>$ Xiangtan. (3) Sb showed a strong migration in paddy soil in the research area and its content increased initially and then decreased or gradually decreased with the increase of profile depth. (4) The content of $\mathrm{Sb}$ in the substratum was significantly affected by parent materials.

Keywords: eastern Hunan Province, paddy soil, antimony, distribution characteristics, parent material

\section{INTRODUCTION}

The heavy metal elements in soils have shown the characteristics of low degradability, intensive perniciousness, high crypticity, and complicated ecological effects, which brought adverse effects to ecological environment and human health. The Bulletin of National Soil Pollution Survey (Ministry of Ecology Environment of the People's Republic of China, 2014) reported that the soil sites exceeding the rate of farmland in China were as high as $19.4 \%$, with mainly inorganic pollutants. Agricultural soils form the basis of all agricultural production activities. As a consequence, these research studies on the distribution characteristics of heavy metals and potential ecological hazards in agricultural soils are of great importance to ensure normal agricultural production activities. As a toxic and harmful heavy metal element, antimony $(\mathrm{Sb})$ has been classified as a priority pollutant by the US Environmental Protection Agency (Callahan, 1980). It has been reported that a longdistance migration of $\mathrm{Sb}$ can be met by atmospheric circulation and river transport (Reimann et al., 2010). In addition, the content of Sb in the Arctic Circle has increased significantly in recent years (Krachler et al., 2005), which confirmed the possibility of transboundary pollution. The content of $\mathrm{Sb}$ in soil crept up gradually owing to the mining and mineral utilization in recent years, which threatened human health and the safety of the ecological system, and thus gradually drawing our attention.

Being the hometown of non-ferrous metals, there were many kinds of non-ferrous metals with large reserves in Hunan Province. Compared with the other heavy metals, Sb reserves were at the forefront of the world. As one of the advantage mineral resources in Hunan Province, it occupied an important position in China and the world (Tang and Tang, 2010). At present, there were $117 \mathrm{Sb}$ ores in Hunan Province (Ding et al., 2013), among them, the tin mine in Lengshuijiang enjoyed the title of "Antimony capital of the world" because of its highest 
$\mathrm{Sb}$ reserves in the world. However, its mining and utilization may not only lead to severe pollution to surrounding soil, but also increase the content of Sb in soils far away from mining areas by a long-distance migration. As a major Sb-producing province, the background value of Sb in soils in Hunan Province was $1.87 \mathrm{mg} / \mathrm{kg}$, which was higher than the national average (Qi and Cao, 1991). In recent years, most research reports of Hunan Province about soil Sb focused on the mining areas (Wang et al., 2010; Li et al., 2017), while only a few reports on the content of $\mathrm{Sb}$ in soils far away from mining areas. According to the distribution of mineral resources in Hunan Province, the spatial distribution of $\mathrm{Sb}$ in an agricultural soil of eastern Hunan Province, which localized east to a line of Tongdao County-Huaihua City-Yuanling County-Yingfengqiao Town in Yiyang City-Chenglingji in Yueyang City, showed strong heterogeneity (Jia et al., 2013). According to the report by Xiang et al. (2011), paddy soil showed the highest content of Sb among the different land-use types. And the intake of Sb in rice accounted for one-third of the total intake of the human body (Wu et al., 2011). Considering that the area of paddy soil in eastern Hunan Province was the largest among the total area of paddy soil in Hunan Province (Yang, 1987) and rice was the main foodstuff product in Hunan Province, eastern Hunan Province was elected. So, the research on the distribution characteristics and migration of $\mathrm{Sb}$ in paddy soil of eastern Hunan Province is of great importance, it can offer basic information about the safe utilization of paddy soil and food security.

\section{MATERIALS AND METHODS}

\section{General Situation of the Research Area}

The research area is localized to eastern Hunan Province with longitude and latitude coordinates of $111^{\circ} 53^{\prime}-114^{\circ} 15^{\prime} \mathrm{E}$ and $26^{\circ} 03^{\prime}-29^{\circ} 51^{\prime} \mathrm{N}$. This area is high in the southeast and low in the northwest, with various types of landforms. The climate in this research area belongs to a middle subtropical monsoon climate, which is hot and rainy in summer and warm and rainy in winter. In this research, the annual mean temperature is $18.2^{\circ} \mathrm{C}$ and the annual average precipitation is $1,510.15 \mathrm{~mm}$. This research area includes Changsha City, Zhuzhou City, Xiangtan City, and Yueyang City, which is one of the most suitable areas for agricultural development.

\section{Sample Collection}

All sampling sites were determined by using an integrated geographical unit. The administrative map, the present land-use map, and the soil map of Hunan Province were overlapped, and the results were corrected by the second general survey of Hunan Province. Firstly, the most representative parent materials in the area were found, and then sampling was carried out in the place where the paddy field was most concentrated. These sampling sites were determined by using a simple random distribution method as shown in Figure 1, and 34 sampling sites were set up and 198 samples were collected. The sampling procedure followed the requirement of "Field soil description and sampling manual." The depth of a profile was $140 \mathrm{~cm}$ with stratified sampling. Each soil sample was composed of at least five sites by

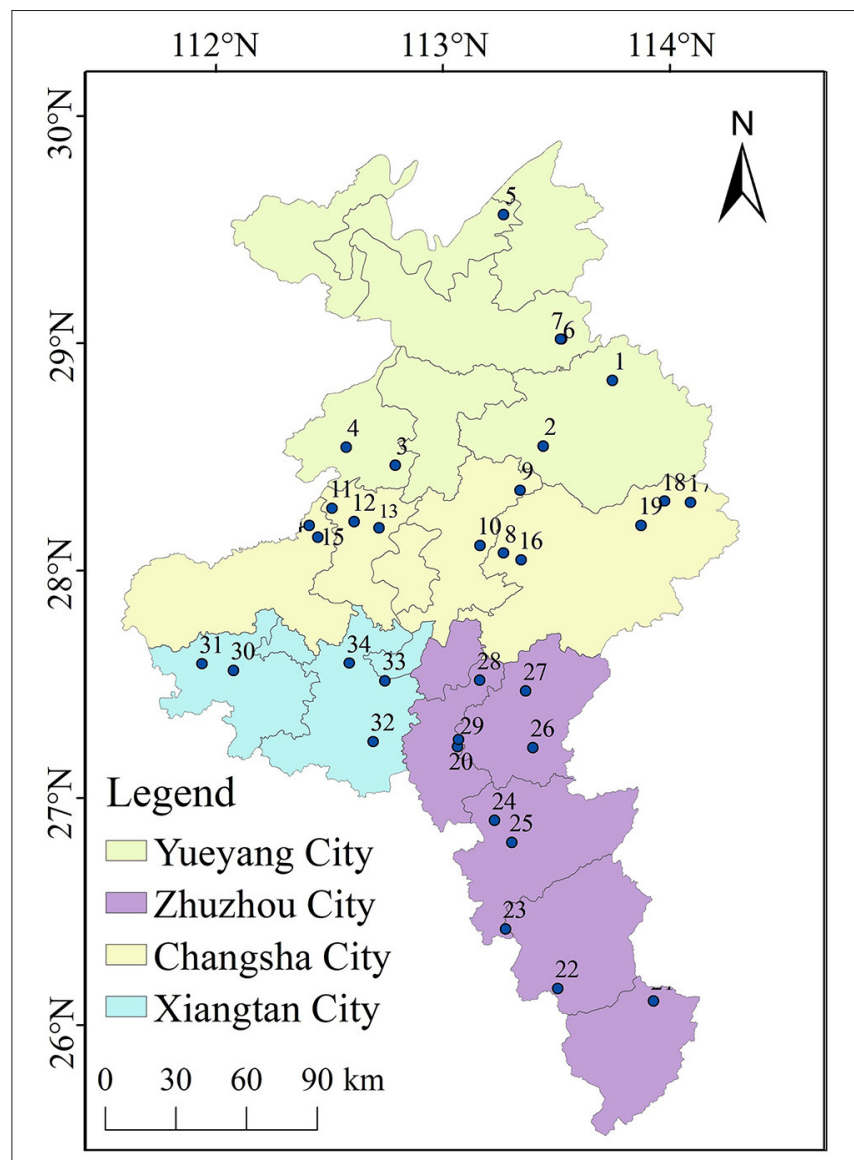

FIGURE 1 | Schematic diagram of the spatial distribution of sampling points.

using an S-shaped sampling method. About $1 \mathrm{~kg}$ of soil sample was prepared by a quarter method and then labeled with serial numbers and global positioning system (GPS) coordinates.

\section{Sample Treatment and Determination}

After removing plant roots and gravel, soil samples were dried in the lab and then grounded for further analysis $(10,60$, and 100 mesh). The total content of $\mathrm{Sb}$ was determined by "Solid and sediment-Determination of aqua regia extracts of 12 metal elements-Inductively coupled plasma mass spectrometry" (HJ 803-2016). The quality of samples passed the standards for the National reference material soil sample, GBW07404 (GSS-4), GBW07405 (GSS-5), and GBW07407 (GSS-7). The determination of physiochemical properties of soils followed "The analysis method of soil agricultural chemistry" (Lu, 2000).

\section{Research Method}

Water washing coefficient (WWC) (Nan and Li, 2000) is used to present a vertical migration of heavy metal, as described in Formula (1):

$$
W W C_{i j}=\frac{M_{(i-1) j}}{M_{i j}}
$$


TABLE 1 | Concentrations of antimony (Sb) on the surface layer of paddy soil.

\begin{tabular}{|c|c|c|c|c|c|c|c|c|}
\hline Max & Min & $\begin{array}{c}\text { Arithmetic } \\
\text { mean }\end{array}$ & $\begin{array}{c}\text { Geometric } \\
\text { mean }\end{array}$ & CV & $\begin{array}{l}\text { Coefficient } \\
\text { of skewness }\end{array}$ & $\begin{array}{l}\text { Coefficient } \\
\text { of kurtosis }\end{array}$ & $\mathrm{pH}$ & K-S test \\
\hline \multicolumn{9}{|c|}{ mg.kg ${ }^{-1}$} \\
\hline 11.00 & 0.07 & 3.10 & 1.56 & 1.13 & 1.294 & 0.109 & $4.70-8.10$ & $\begin{array}{l}\text { logarithmic normal } \\
\text { distribution }\end{array}$ \\
\hline
\end{tabular}

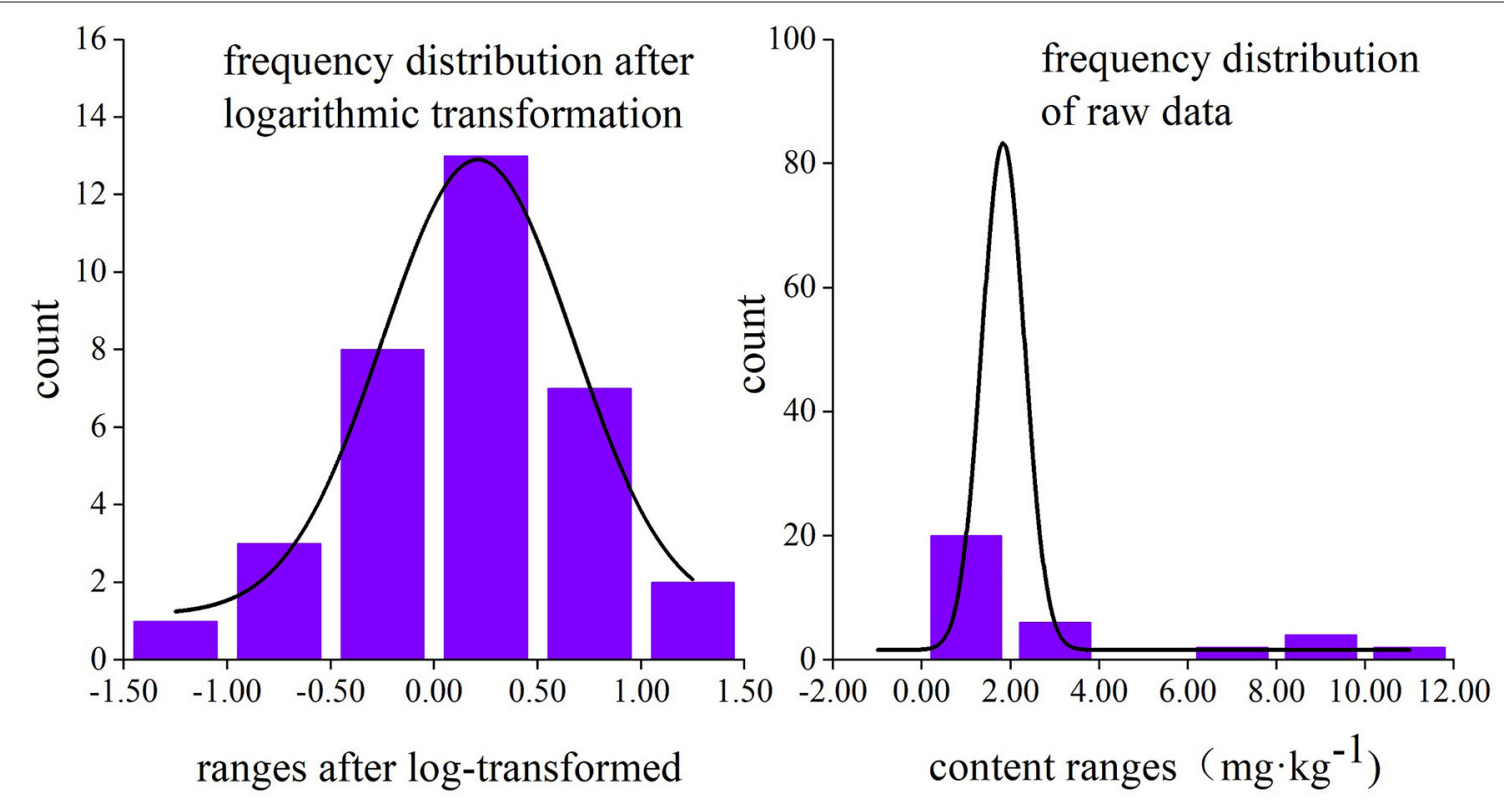

FIGURE 2 | Frequency distribution of antimony (Sb) on the surface layer of paddy soil.



Formula (1): $M_{(i-1) j}$ is the mean content of heavy metal $j$ in layer $(i-1), M_{i j}$ is the mean content of heavy metal $j$ in layer $i$. A higher WWC ratio means a stronger vertical migration of heavy metal.

\section{RESULTS AND ANALYSIS}

\section{The Horizontal Distribution Characteristics of Sb}

The statistics summary of the content of $\mathrm{Sb}$ in the topsoil of paddy soil in eastern Hunan Province was analyzed by using SPSS22 and listed in Table 1. An approximate logarithmic normal distribution was observed for the data of the surface layer, and the frequency distribution was shown in Figure 2. The coefficient of variation was 1.13 , this high value shall be caused by multiple sampling sites with high contents of Sb. If the mean content of $\mathrm{Sb}$ is presented as arithmetic mean, the content of $\mathrm{Sb}$ of paddy soil in the research area will be artificially increased. Since the content of $\mathrm{Sb}$ followed a normal distribution after a logarithmic transformation, it would be more reasonable to use the geometric mean value to express the average content of $\mathrm{Sb}$ on the surface of paddy soil (Chen et al., 1991). From Table 1, it was observed that the content of $\mathrm{Sb}$ of the surface of paddy soil in eastern Hunan Province fell in a region of $0.07-$ $11.00 \mathrm{mg} / \mathrm{kg}$, and the geometric mean was $1.56 \mathrm{mg} / \mathrm{kg}$, which was close to the background value of the content of $\mathrm{Sb}$ in soils in Hunan Province $(1.87 \mathrm{mg} / \mathrm{kg})$. This result suggested that the mean content of $\mathrm{Sb}$ on the surface of paddy soil in eastern Hunan Province stayed in a clean condition, and the impact of human activities was small. The $\mathrm{pH}$ value fell in a region of 


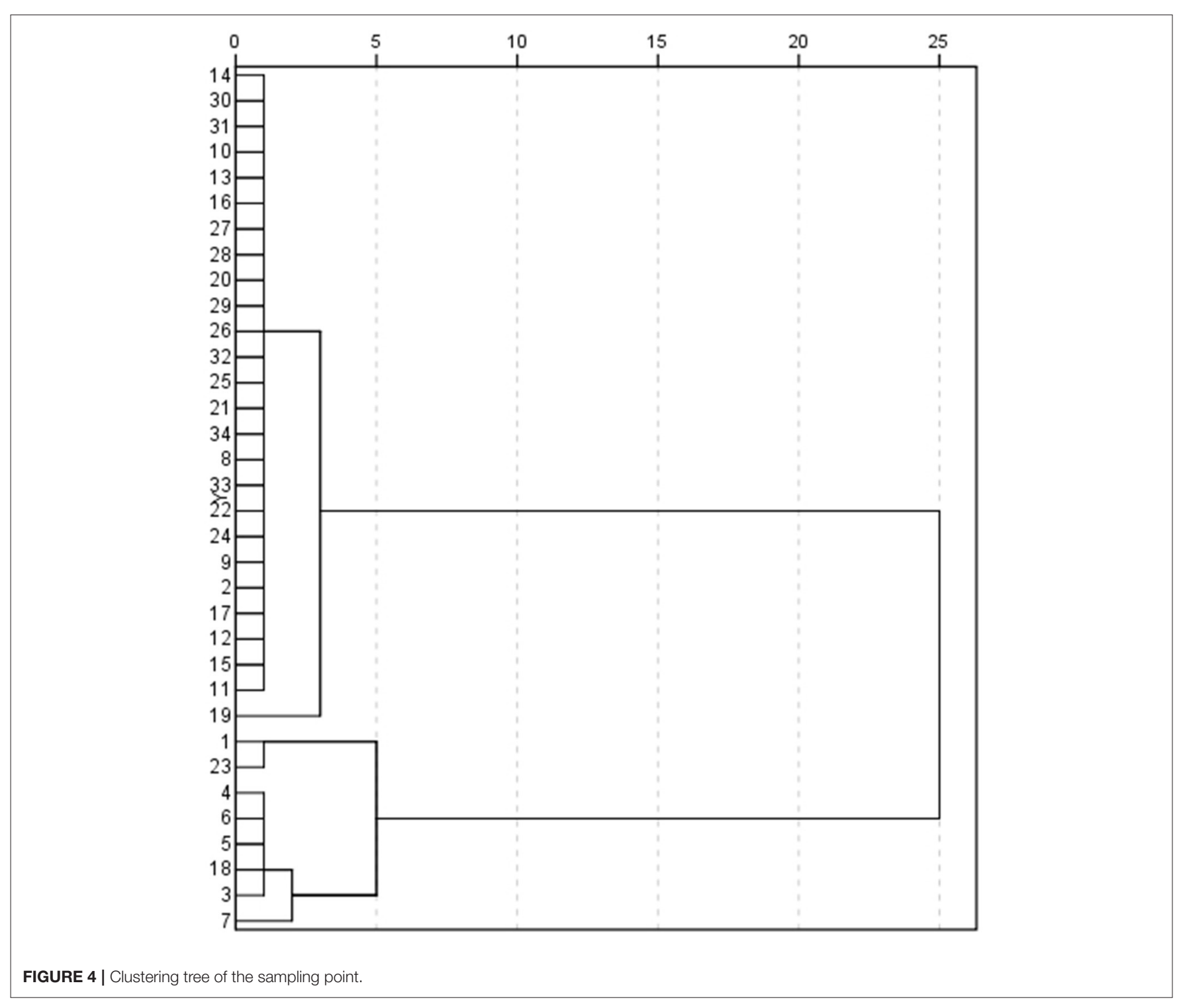

$4.70-8.10$ with a mean value of 5.67 , the soil environment was slightly acidic.

The content of $\mathrm{Sb}$ in different cities were showed in Figure 3. The contents of Sb on the surface of paddy soil in Changsha City, Zhuzhou City, Xiangtan City, and Yueyang City were 0.67$9.32,0.07-6.93,0.14-1.60,0.91-11.00 \mathrm{mg} / \mathrm{kg}$, respectively. The contents of $\mathrm{Sb}$ in some sampling sites were higher than the background value of the content of Sb in soils in China (0.38$2.98 \mathrm{mg} / \mathrm{kg}$ ) (Qi and Cao, 1991). The distribution of the contents of $\mathrm{Sb}$ followed an order of Yueyang City $>$ Changsha City $>$ Zhuzhou Sity $>$ Xiangtan City. The highest value was found in the southeast of Xiangyin County in Yueyang City, and the lowest value was found in the middle and western of You County in Zhuzhou City, the difference of the content of Sb between them was $10.93 \mathrm{mg} / \mathrm{kg}$. According to the Nielsen grading standard, the content of $\mathrm{Sb}$ on the surface of paddy soil in the research area was classified as a medium to strong variation. In Zhuzhou City, the variation coefficient of the content of Sb on the surface of paddy soil showed the highest value of 1.12 . Such a high coefficient of variation indicated that some sample sites have shown higher contents of $\mathrm{Sb}$ on the surface of paddy soil in this area, which shall have a high possibility of correlation with human activities, this observation is consistent with the feature that Zhuzhou City is the biggest industrial city in Hunan Province. The variation coefficient of the content of $\mathrm{Sb}$ on the surface of paddy soil in Yueyang City showed the lowest value of 0.44 . However, the average content of $\mathrm{Sb}$ was much higher than the background value in Hunan Province, indicating a high cumulativeness of the content of $\mathrm{Sb}$ on the surface of paddy soil in this area. This result shall be attributed to the terrain reason of "low in north and high in south" in eastern Hunan Province, which made a longdistance migration of $\mathrm{Sb}$ easy to deposit. To find out if there was a significant difference between the content of $\mathrm{Sb}$ of various areas, the contents of $\mathrm{Sb}$ of the surface layer of paddy soil in different 


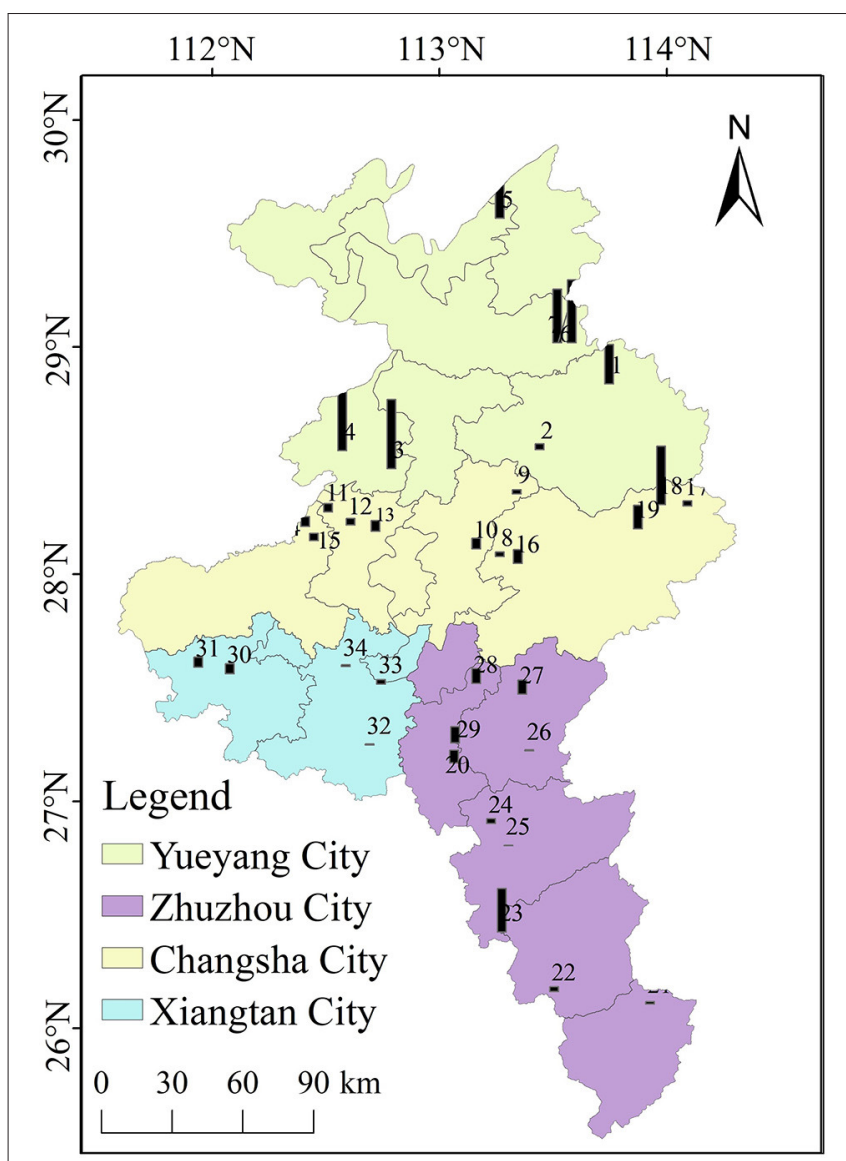

FIGURE 5 | Contents of Sb in different sampling sites.

areas were analyzed by using the ANOVA method. According to the inspection results, there was no significant difference between the contents of Sb on the surface of paddy soil in Changsha City, Zhuzhou City, and Xiangtan City, but the content of Sb on the surface of paddy soil in Yueyang City was obviously higher than those in other areas $(p<0.05)$.

After classifying all sampling sites from different areas with a hierarchical cluster method, those with high correlation shall be classified together and their content of $\mathrm{Sb}$ had similar characteristics. A clustering method was the link between the different groups, the hierarchical clustering result was shown in Figure 4. All sampling sites have been classified into three groups with an interclass distance of five. The first group included sampling sites of $2,8-10,13-14,16,20-22,25-34$, which were mainly localized in the middle and south of the research area. Their contents of Sb were nearly the same as the background value of $\mathrm{Sb}$ in Hunan Province. The second group included sampling sites of 1,23 , and the third group included sampling sites of 3-7, 18, which were mainly localized in the north of the research area. The average content of $\mathrm{Sb}$ in the second and third sampling points was 6.59 and $9.80 \mathrm{mg} / \mathrm{kg}$, respectively. Their contents of $\mathrm{Sb}$ were higher than the background value of $\mathrm{Sb}$ in Hunan Province. This result suggested that the content of $\mathrm{Sb}$ in the north of the research area was relatively high, showing a

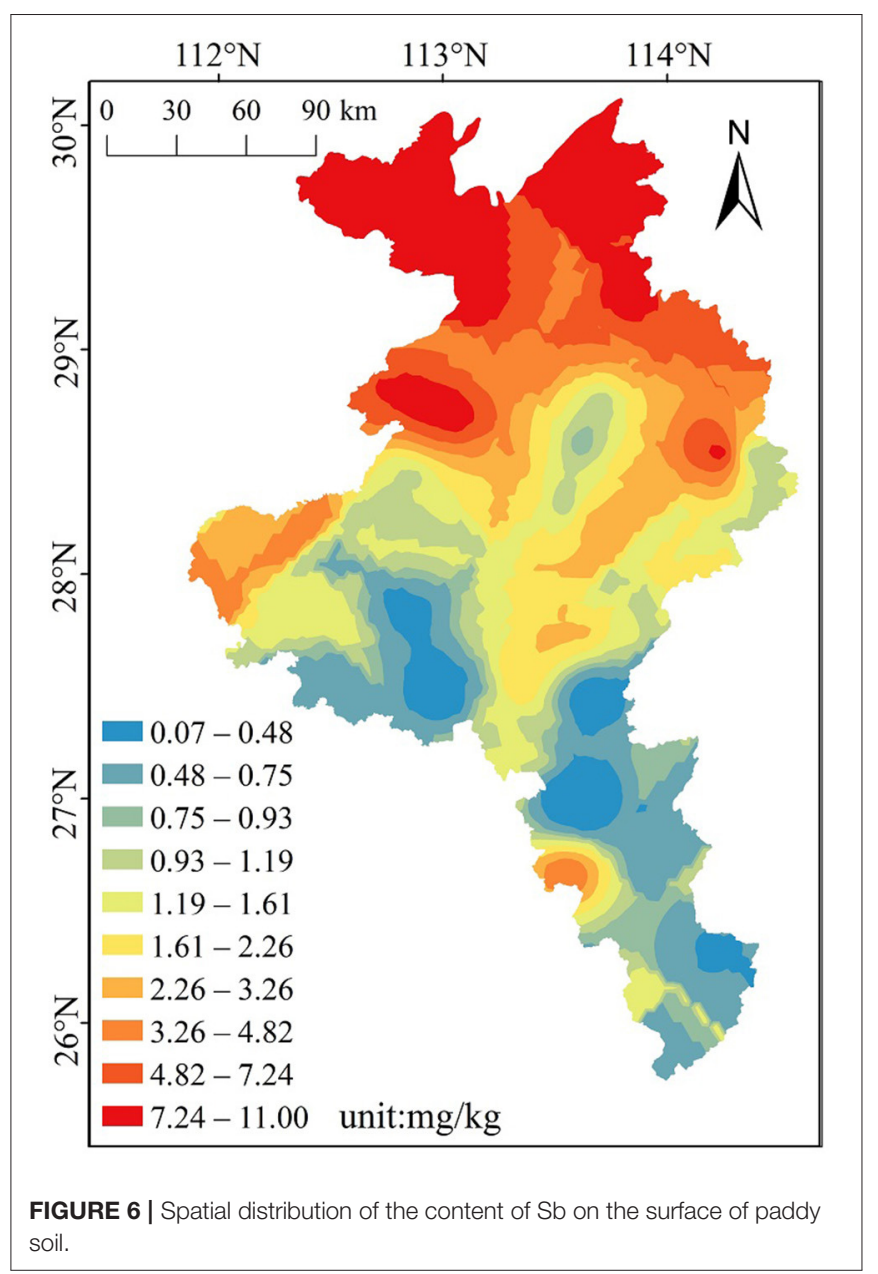

decreasing tendency from north to south. The spatial distribution of the content of $\mathrm{Sb}$ in north Hunan Province was shown in Figures 5, 6. In the south, sampling sites with a high content of $\mathrm{Sb}$ were located in Liling County and Zhuzhou City, which were related to the local industrial activities.

The difference in the content of $\mathrm{Sb}$ among various areas can be reflected by comparing the content of $\mathrm{Sb}$ in the soils. The background value of $\mathrm{Sb}$ in various areas is different owing to the influence from soil parent materials, soil-forming processes, human activities, etc. during the soil formation. If we only compare the content of Sb in different areas, we will artificially magnify the impacts of Sb on the environment in high background value areas and ignore the impacts of $\mathrm{Sb}$ on the environment in low background value areas. As a consequence, this work used a relative content (measured value: background value) to compare the content of $\mathrm{Sb}$ in soils in various areas. It was observed from Table 2 that the contents of $\mathrm{Sb}$ in soils in different landforms and different areas were different. The relative contents of $\mathrm{Sb}$ in mine soils and agricultural soils around the mining areas were much higher than those of other areas, showing a high accumulation of $\mathrm{Sb}$. As for those soils far away from the mining areas, the relative content of $\mathrm{Sb}$ of paddy soil in Yueyang City showed the highest value of 4.33 , which was 
TABLE 2 | Comparison of Sb in topsoil from different regions.

\begin{tabular}{|c|c|c|c|c|c|c|c|}
\hline & Region & $\operatorname{Max}$ & Min & Mean & Background & $\begin{array}{l}\text { Relative content } \\
\text { (measured value/background value) }\end{array}$ & References \\
\hline \multicolumn{8}{|l|}{$\mathbf{m g} \cdot \mathbf{k g}^{-1}$} \\
\hline Measured in & Changsha & 6.40 & 0.61 & 2.16 & 1.87 & 1.16 & - \\
\hline \multirow[t]{3}{*}{ this study } & Zhuzhou & 8.19 & 0.05 & 1.83 & 1.87 & 0.98 & - \\
\hline & Xiangtan & 1.86 & 0.67 & 0.85 & 1.87 & 0.45 & - \\
\hline & Yueyang & 11.19 & 0.91 & 8.09 & 1.87 & 4.33 & - \\
\hline \multicolumn{2}{|c|}{ Honghe Farm, Sanjiang Plain } & - & - & 2.89 & 0.91 & 3.17 & Liu et al., 2019 \\
\hline \multicolumn{2}{|c|}{$\begin{array}{l}\text { Farmland in downstream region of } \\
\text { Yuxi River }\end{array}$} & 34.4 & 41.03 & 12.26 & 1.87 & 6.56 & Fei et al., 2017 \\
\hline \multicolumn{2}{|c|}{ Xikuangshan in Hunan Province } & 5,045 & 100 & 695 & 1.87 & 371.66 & $\mathrm{He}, 2007$ \\
\hline \multicolumn{2}{|c|}{$\begin{array}{l}\text { Guizhou dushan county antimony } \\
\text { smelter }\end{array}$} & 98.52 & 5.02 & 26.65 & 2.24 & 11.90 & Xiong et al., 2020 \\
\hline \multicolumn{2}{|l|}{ Dalian } & 1.79 & 0.24 & 1.01 & 0.84 & 1.20 & MEMSC, 1990 \\
\hline \multicolumn{2}{|l|}{ Wenzhou } & 2.82 & 0.46 & 0.74 & 1.53 & 0.48 & \\
\hline \multicolumn{2}{|l|}{ Ningbo } & 1.48 & 0.61 & 0.92 & 1.53 & 0.60 & \\
\hline \multicolumn{2}{|l|}{ Xiamen } & 0.81 & 0.22 & 0.45 & 0.65 & 0.69 & \\
\hline \multicolumn{2}{|l|}{ Shenzhen } & 2.72 & 0.21 & 0.76 & 0.54 & 1.41 & \\
\hline
\end{tabular}

similar to the relative content of Sb of agricultural soil in Honghe Farm of Sanjiang Plain. The relative content of Sb of paddy soil in Xiangtan City showed the lowest value of 0.45 . According to the comparison of the relative content of Sb between different areas, it was found that the accumulation of Sb in paddy soil in Yueyang City was relatively high, while that of Changsha City, Zhuzhou City, and Xiangtan City was relatively low.

\section{The Vertical Distribution Characteristics of $\mathrm{Sb}$}

After a long cultivating history, the distribution characteristics of content of $\mathrm{Sb}$ have changed in profiles, rendering a comprehensive influence of multiple factors. The distribution characteristics of $\mathrm{Sb}$ under the influence of multiple factors cannot be clearly explained by simply analyzing the content of $\mathrm{Sb}$ on the surface of paddy soil. The analysis of the vertical distribution of $\mathrm{Sb}$ in a profile was helpful to have a precise understanding of the distribution characteristics and migration of Sb. In conclusion, the content of Sb in the research area showed a complicated correlation with the increase of soil depth, its content mainly increased firstly and then decreased or gradually decreased. The detailed distribution characteristics in a profile were shown in Figure 7.

It was observed from Figure 7 that, as for the first type of profile, the content of Sb firstly increased and then decreased. It showed that the migration of $\mathrm{Sb}$ in the plow layer and the accumulation of $\mathrm{Sb}$ in the plow pan were greatly affected by external sources. More specifically, the content of $\mathrm{Sb}$ varied in a wide range of $0-40 \mathrm{~cm}$, which firstly increased and then decreased, and the maximum value was observed at $20 \mathrm{~cm}$. The content of $\mathrm{Sb}$ below $40 \mathrm{~cm}$ varied in a narrow range and showed a decreasing tendency. The maximum content of $\mathrm{Sb}$ in this profile was obviously higher than that in other profiles. This tendency was mainly observed from the sampling sites in Liling County of Zhuzhou City and Yueyang City. Yueyang City is rich in mineral resources, and Liling County is rich in coal resources.
As a common trace element in metal sulfide ore and coal (Qi et al., 2008), Sb can be released into soil via various paths, including mining, smelting, transportation, and utilization, and then it finally accumulated in the plow pan by leaching migration during tillage.

As for the second type of profile, the content of Sb gradually decreased, indicating a decreased migration with an increase of this profile. This result was consistent with the report by Cai et al. (2020) on the vertical migration characteristics of Sb in farmland soil contaminated by dam break of Huashan tailings pond in Anhui Province. In agricultural activities, the use of pesticides and chemical fertilizers increased the content of organic matter in the surface soil, which enhanced the adsorption of organic matter for $\mathrm{Sb}$, leading to a decreased vertical migration in this profile. As for the first situation, the content of Sb decreased smoothly, and as for the second situation, the content of $\mathrm{Sb}$ decreased dramatically in $15-35 \mathrm{~cm}$ and then smoothly decreased below $35 \mathrm{~cm}$. There was a common feature for the second situation, which was the high content of Sb in the top of soils.

As for the third type of profile, the content of Sb firstly decreased and then increased. The lowest contents of Sb of some profiles were observed at $30 \mathrm{~cm}$, while those of other profiles were observed at $70 \mathrm{~cm}$. The content of $\mathrm{Sb}$ of sampling site number two varied in a wide range, showing an obvious decreasing tendency in the surface soil and an obvious increasing tendency in the deep soil. The content of $\mathrm{Sb}$ of other sampling sites fell in a narrow region. The different varying tendencies were related with the parent materials and physiochemical properties of soils. If the soil clay content was low in the middle soil and high in the deep soil, a decreasing tendency would be firstly observed and then followed by an increasing tendency (Shi et al., 2016). Under the influence of parent materials, their content may increase gradually with the depth of a profile (Yang et al., 2020).

As for the fourth type of profile, the content of Sb showed a fluctuational tendency with increasing depth. It is assumed that paddy soil is water saturated in the plowing season but 


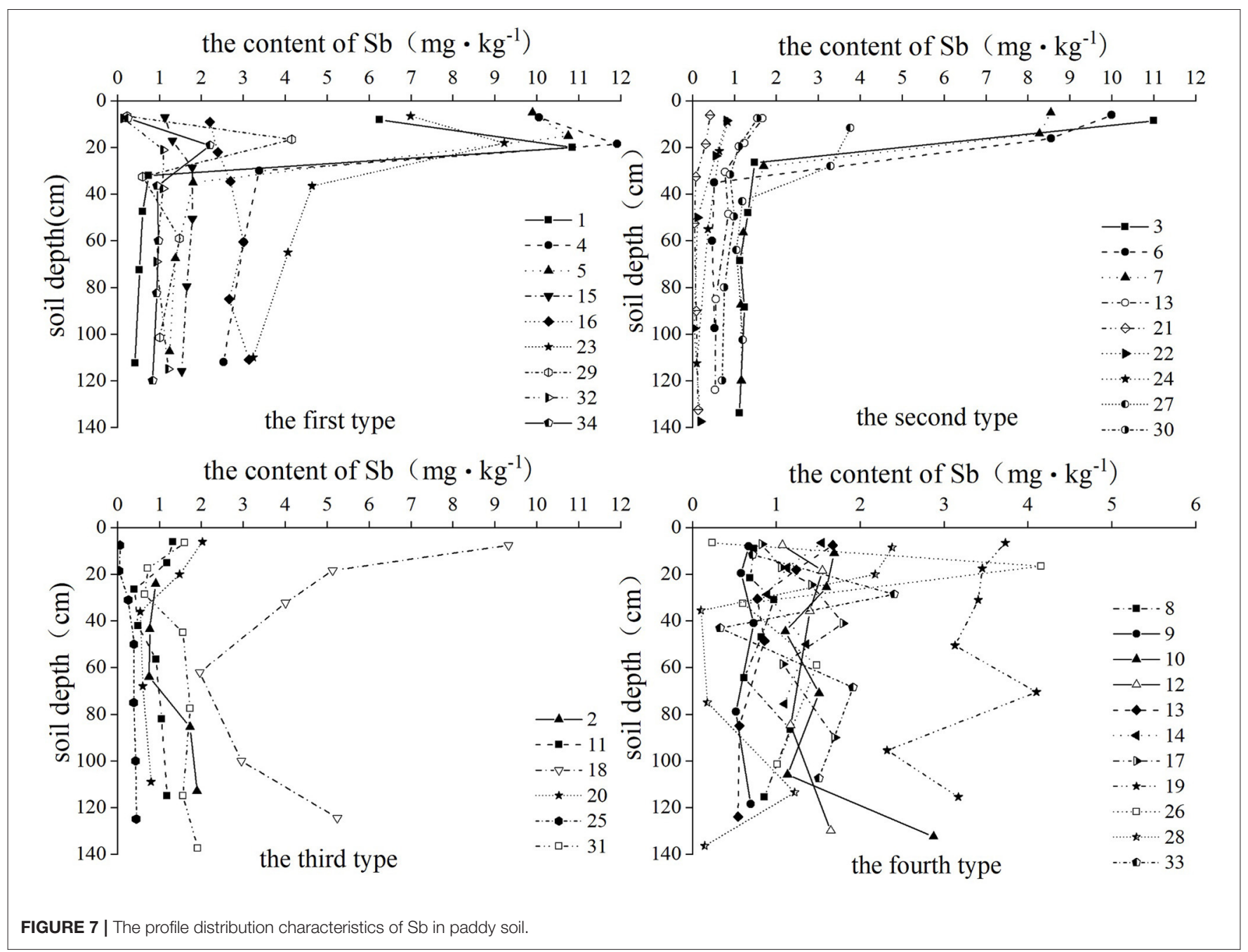

water deficient in the non-plowing season, which leads to a periodic oxidation-reduction reaction of paddy soil. As a consequence, a vertical migration of $\mathrm{Sb}$ occurred in profiles in the research area. The difference of contents of Sb of all profiles with the same depth varied in a wide range. The biggest difference of $4.00 \mathrm{mg} / \mathrm{kg}$ showed at $70 \mathrm{~cm}$, while the smallest difference of $0.09 \mathrm{mg} / \mathrm{kg}$ showed at $5 \mathrm{~cm}$. Although there was no obvious correlation between the contents of $\mathrm{Sb}$ of different profiles with increasing depth, a similarity was observed as the fact that the sampling sites with a high content of $\mathrm{Sb}$ in the surface soil had a high content of $\mathrm{Sb}$ in the bottom soil.

For a clear understanding of leaching migration characteristics in the vertical profile of $\mathrm{Sb}$, WWC was used. The formula introduced in the research method was used for calculation. The WWC values of $\mathrm{Sb}$ in the plow layer and plow pan were calculated as 1.08 and 0.32 , respectively, indicating a stronger migration of $\mathrm{Sb}$ in the plow layer than in the plow pan. Although the WWC value of the plow pan was relatively low, the downward migration of $\mathrm{Sb}$ in paddy soil of the research area was relatively high in the whole profiles. This result was consistent with the migration characteristics of soil $\mathrm{Sb}$ near Xikuangshan mining areas (Yang et al., 2015). Such Sb migration characteristics were related to the acidic soil in the research area. The low WWC value of the plow pan was due to the higher content of $\mathrm{Sb}$ in the plow pan, which decreased the relative downward leaching loss.

\section{Characteristics of the Content of Sb in Different Soil Parent Materials}

The heavy metals in soil parent materials are the original sources of soil heavy metals. Different soil parent materials have different heavy metal contents, which are responsible for the initial difference in heavy metal contents between different areas (de Souza et al., 2015). By analyzing the difference of contents of $\mathrm{Sb}$ between the paddy soils originated from various soil parent materials, it is helpful to understand the reasons for a relatively high heavy metal content in the research area. The content characteristics of $\mathrm{Sb}$ in paddy soils developed on various soil parent materials were listed in Table 3. 
TABLE 3 | The content of Sb in paddy soil formed by different parent soils.

\begin{tabular}{|c|c|c|c|c|c|c|c|}
\hline \multicolumn{2}{|c|}{$\begin{array}{l}\text { Parent materials } \\
\text { (numbers of sampling sites) }\end{array}$} & $\begin{array}{c}\text { Granite } \\
\text { weathering } \\
(n=9)\end{array}$ & $\begin{array}{l}\text { Plate shale } \\
\text { weathering } \\
\quad(n=7)\end{array}$ & $\begin{array}{l}\text { Quaternary red } \\
\text { clay } \\
(n=9)\end{array}$ & $\begin{array}{l}\text { Fluvial } \\
\text { sediment } \\
(n=3)\end{array}$ & $\begin{array}{l}\text { Purple sandy } \\
\text { shale } \\
\text { weathering } \\
(n=5)\end{array}$ & $\begin{array}{l}\text { The combination of } \\
\text { purple sand weathering } \\
\text { and Quaternary red clay } \\
\qquad(n=1)\end{array}$ \\
\hline \multicolumn{8}{|l|}{$\mathbf{m g} \cdot \mathbf{k g}^{-1}$} \\
\hline Plow layer & Range & $0.42-9.99$ & $0.14-9.90$ & $0.07-11.00$ & $0.72-10.05$ & $0.23-3.73$ & 0.82 \\
\hline$(n=34)$ & Mean & 2.73 & 4.49 & 3.31 & 3.95 & 1.40 & - \\
\hline Plow pan & Range & $0.32-10.86$ & $0.73-10.75$ & $0.05-8.27$ & $1.55-11.92$ & $0.69-4.16$ & 0.56 \\
\hline$(n=34)$ & Mean & 2.94 & 5.25 & 2.52 & 5.29 & 2.40 & - \\
\hline Substratum & Range & $0.09-1.87$ & $1.08-3.77$ & $0.40-2.96$ & $1.30-2.83$ & $0.67-3.12$ & 0.10 \\
\hline$(n=34)$ & Mean & 0.62 & 2.10 & 1.32 & 1.85 & 1.33 & - \\
\hline
\end{tabular}

It was observed from Table 3 that the highest content of $\mathrm{Sb}$ was observed from the plow pan of paddy soil originated from a fluviolacustrine sedimentary deposit, while the lowest content of $\mathrm{Sb}$ was observed from the substratum of paddy soil originated from the combination of purple sand weathering and quaternary red clay. The contents of Sb s of paddy soil in the plow layer originated from various parent materials followed an order from high to low of plate shale weathering $>$ fluviolacustrine sedimentary deposit $>$ quaternary red clay $>$ granite weathering $>$ purple sand shale weathering $>$ the combination of purple sand weathering and quaternary red earth. The content of Sb of paddy soil originated from quaternary red earth varied in the widest region, while that from purple sand shale weathering varied in the narrowest region. The contents of Sb of paddy soil in the plow pan originated from various parent materials followed an order from high to low of fluviolacustrine sedimentary deposit $>$ plate shale weathering $>$ granite weathering $>$ quaternary red clay $>$ purple sand shale weathering $>$ the combination of purple sand weathering and quaternary red earth. The content of $\mathrm{Sb}$ of paddy soil originated from granite weathering varied in the widest region, while that from purple sand shale weathering varied in the narrowest region. The contents of $\mathrm{Sb}$ of paddy soil in the substratum originated from various parent materials followed an order from high to low of plate shale weathering $>$ fluviolacustrine sedimentary deposit $>$ purple sand shale weathering $>$ quaternary red clay $>$ granite weathering. The content of $\mathrm{Sb}$ of paddy soil originated from plate shale weathering varied in the widest region, while that from a fluviolacustrine sedimentary deposit varied in the narrowest region.

It has been reported $(\mathrm{Wu}, 2014)$ that the heavy metal contents of surface soil were affected by both soil parent materials and human activities, representing the second environment of soil. While the deep soil suffered from minor human activities, representing the features of soil primary layers, so the heavy metal contents were mainly controlled by soil parent materials. The variation coefficients of paddy soils originated from different parent materials in the plow layer, plow pan, and substratum were determined as $0.41,0.58$, and 0.61 , respectively. The highest variation coefficients of the substratum suggested that the content of $\mathrm{Sb}$ in this layer was most affected by parent materials. For a further understanding of the effect of parent materials on the content of $\mathrm{Sb}$ in different soil layers, ANOVA was performed by using the soil parent material as the only factor. No significant difference was observed for the content of Sb of paddy soil in the plow layer and plow pan between the different soil parent materials. This result suggested that the soil parent materials had no obvious effects $(p>0.05)$ on the content of Sb on the surface of paddy soil. A high content of Sb in a sampling site was caused by human factors, geographical positions, climate conditions, and biological effects. There were significant differences between the content of $\mathrm{Sb}$ of paddy soil in the substratum originated from granite weathering and those from other soil parent materials $(p<0.05)$, which meant that soil parent materials had an obvious effect on the content of $\mathrm{Sb}$ of paddy soil in the substratum.

\section{CONCLUSIONS}

(1) The content of $\mathrm{Sb}$ on the surface of paddy soil fell in a region of $0.07-11.00 \mathrm{mg} / \mathrm{kg}$ with a geometric mean of 1.56 $\mathrm{mg} / \mathrm{kg}$, indicating a clean condition with minor effects from human activities.

(2) The distribution of contents of Sb in paddy soil of various areas followed an order of Yueyang City $>$ Changsha City $>$ Zhuzhou City $>$ Xiangtan City. The highest value was found in the southeast of Xiangyin County in Yueyang City, and the lowest value was found in the central and western of You County in Zhuzhou City.

(3) The content of $\mathrm{Sb}$ showed a strong migration with the increase of profile depth in the research area, and its content increased firstly and then decreased or gradually decreased.

(4) ANOVA was performed on the content of $\mathrm{Sb}$ of paddy soil in different soil layers by using soil parent materials as a factor. It was found that soil parent materials had obvious effects on the content of $\mathrm{Sb}$ of the substratum, but minor effects on the content of $\mathrm{Sb}$ of the plow layer and plow pan. 


\section{DATA AVAILABILITY STATEMENT}

The raw data supporting the conclusions of this article will be made available by the authors, without undue reservation.

\section{AUTHOR CONTRIBUTIONS}

CW, HW, JC, and NO carried out the determination of the content of $\mathrm{Sb}$ and the physical and chemical properties. CW, $\mathrm{DW}, \mathrm{XC}, \mathrm{YZ}$, and $\mathrm{CT}$ participated in discussing the results. CW

\section{REFERENCES}

Cai, Y., Shao, L., Fan, X., Li, Y., Meng, F., and Zhang, H. (2020). Release and vertical migration characteristics of $\mathrm{As}$ and $\mathrm{Sb}$ in farmland soil polluted by dam break of Huashan tailing reservoir in Anhui province environmental chemistry. Environ. Chem. 39, 2479-2489. doi: 10.7524/j.issn.0254-6108.2020041303

Callahan, M. A. (1980). Water-Related Environmental Fate of 129 Priority Pollutants. Office of Water Planning and Standards, Office of Water and Waste Management, US Environmental Protection Agency.

Chen, J., Wei, F., Zheng, C., Wu, Y., and Adriano, D. C. (1991). Background concentrations of elements in soils of China. Water Air Soil Pollut. 57, 699-712. doi: 10.1007/BF00282934

de Souza, J., Abrahão, W., de Mello, J., da Silva, J., da Costa, M., and de Oliveira, T. (2015). Geochemistry and spatial variability of metal (loid) concentrations in soils of the state of Minas Gerais, Brazil. Sci. Tot. Environ. 505, 338-349. doi: 10.1016/j.scitotenv.2014.09.098

Ding, J., Yang, Y., and Deng, F. (2013). Resource potential and metallogenic prediction of antimony ore in China. Geol. China 40, 846-858.

Fei, J., Min, X., Wang, Z., Pang, Z., Liang, Y., and Ke, Y. (2017). Health and ecological risk assessment of heavy metals pollution in an antimony mining region: a case study from South China. Environ. Sci. Pollut. Res. 24, 27573-27586. doi: 10.1007/s11356-017-0310-x

He, M. (2007). Distribution and phytoavailability of antimony at an antimony mining and smelting area, Hunan, China. Environ. Geochem. Health 29, 209-219. doi: 10.1007/s10653-006-9066-9

Jia, B., Huang, G., and Sun, H. (2013). Report on the Evaluation Results of Mineral Resources Potential in Hunan Province. Changsha: Hunan Provincial Geological Survey Institute.

Krachler, M., Zheng, J., Koerner, R., Zdanowicz, C., Fisher, D., and Shotyk, W. (2005). Increasing atmospheric antimony contamination in the northern hemisphere:Snow and ice evidence from Devon Island, Arctic Canada. J. Environ. Monit. 7, 1169-1176. doi: 10.1039/b509373b

Li, X., Yang, H., Zhang, C., Zeng, G., Liu, Y., Xu, W., et al. (2017). Spatial distribution and transport characteristics of heavy metals around an antimony mine area in central China. Chemosphere 170, 17-24. doi: 10.1016/j.chemosphere.2016.12.011

Liu, Z., Wang, G., Fang, Y., Jiang, M., Liu, C., Yao, X., et al. (2019). Contents of 55 elements in natural swamp, returning farmland to wetlands and farmland surface soil of Honghe farm in Sanjiang plain wetland. Science 17, 713-717. doi: 10.13248/j.cnki.wetlandsci.2019.06.015

Lu, R. (2000). Methods for Agricultural Chemical Analysis of Soil. Beijing: China Agricultural Science and Technology press.

MEMSC (1990). The Background Values of Soil Elements in China. Beijing: Meterological Press.

Ministry of Ecology and Environment of the People's Republic of China (2014). Ministry of Natural Resources of the People's Republic of China. Bulletin of the National Survey on Soil Pollution. Beijing.

Nan, Z., and Li, J. (2000). Profile distribution and behavior of heavy metals cadmium, lead and nickel in cultivated soil in arid area-taking calcareous soil in Baiyin city as an example. Arid Zone Res. 17, 39-45. prepared the draft of the manuscript. DW and CW revised the manuscript. All authors contributed to the article and approved the submitted version.

\section{FUNDING}

This research was supported by Hunan Innovative Province Construction Special Fund (2020NK2001) and the Natural Science Foundation of Changsha (kq2007082).

Qi, C., Liu, G., Chou, C. L., and Zheng, L. (2008). Environmental geochemistry of antimony in Chinese coals. Sci. Tot. Environ. 389, 225-234. doi: 10.1016/j.scitotenv.2007.09.007

Qi, W., and Cao, J. (1991). Study on soil environmental background value of antimony. Chin. J. Soil Sci. 22, 209-210.

Reimann, C., Matschullat, J., Birke, M., and Salminen, R. (2010). Antimony in the environment: lessons from geochemical mapping. Appl. Geochem. 25, 175-198. doi: 10.1016/j.apgeochem.2009.11.011

Shi, Y., Yue, R., and Zhang, H. (2016). Study on vertical stratification of heavy metals in soil around nonferrous metals mining and smelting base. Chin. J. Soil Sci. 47, 186-191. doi: 10.19336/j.cnki.trtb.2016.01.029

Tang, W., and Tang, X. (2010). Select the strategic reserve variety of superiority mineral resources in Hunan. Non Ferrous Mining Metallurgy 26, 57-59.

Wang, X., He, M., Xie, J., Xi, J., and Lu, X. (2010). Heavy metal pollution of the world largest antimony mine-affected agricultural soils in Hunan province (China). J. Soils Sediments 10, 827-837. doi: 10.1007/s11368-010-0196-4

Wu, F., Fu, Z., Liu, B. J., Mo, C., Chen, B., Corns, W., et al. (2011). Health risk associated with dietary co-exposure to high levels of antimony and arsenic in the world's largest antimony mine area. Sci. Tot. Environ. 409:3344. doi: 10.1016/j.scitotenv.2011.05.033

Wu, H. (2014). Distribution Characteristics of Heavy Metal Elements and Influence of Parent Materials in Soils of Hainan Province. Beijing: China University of Geosciences.

Xiang, M., Zhang, G., Li, L., Wei, X., and Cai, Y. (2011). Distribution of heavy metal pollution in surface soil of lead-antimony smelting area in Guangxi. Acta Mineral. Sin. 31, 250-255. doi: 10.16461/j.cnki.1000-4734.2011.02.004

Xiong, J., Han, Z., Wu, P., Zeng, Y., Luo, G., and Yang, W. (2020). Spatial distribution, pollution assessment and health risk assessment of antimony and arsenic in soils around Dushan antimony smelter. Acta Sci. Circumstantiae 40, 655-664. doi: 10.13671/j.hjkxxb.2019.0387

Yang, F. (1987). Hunan Soil[M]. Beijing: China Agriculture Press.

Yang, H., He, M., and Wang, X. (2015). Concentration and speciation of antimony and arsenic in soil profiles around the world's largest antimony metallurgical area in China. Environ. Geochem. Health 37, 21-33. doi: 10.1007/s10653-014-9627-2

Yang, S., Jin, G., Fang, Q., Liao, S., Luo, W., Jia, J., et al. (2020). Review on analysis of soil heavy metal pollution sources in China in recent ten years (2009-2018). Jiangsu Agric. Sci. 48, 17-24. doi: 10.15889/j.issn.1002-1302.2020.20.003

Conflict of Interest: The authors declare that the research was conducted in the absence of any commercial or financial relationships that could be construed as a potential conflict of interest.

Copyright (c) 2021 Wang, Wan, Cao, Wang, Chen, Ouyang, Zhang and Tan. This is an open-access article distributed under the terms of the Creative Commons Attribution License (CC BY). The use, distribution or reproduction in other forums is permitted, provided the original author(s) and the copyright owner(s) are credited and that the original publication in this journal is cited, in accordance with accepted academic practice. No use, distribution or reproduction is permitted which does not comply with these terms. 